\title{
Uninsured Primary Care Visit Disparities Under the Affordable Care Act
}

\author{
Heather Angier, MPH \\ Megan Hoopes, $\mathrm{MPH}^{2}$ \\ Miguel Marino, $\mathrm{PbD}^{1}$ \\ Natbalie Huguet, $P b D^{1}$ \\ Elizabeth A. Jacobs, MD, MAPP \\ Jobn Heintzman, MD, MPH ${ }^{1}$ \\ Heather Holderness, MPH \\ Carlyn M. Hood, MPA, MPH' \\ Jennifer E. DeVoe, MD, DPbil ${ }^{1}$ \\ 'Oregon Health \& Science University, \\ Portland, Oregon
}

${ }^{2} \mathrm{OCHIN}$, Inc, Portland, Oregon

${ }^{3}$ University of Wisconsin School of Medicine and Public Health, Madison, Wisconsin

Conflicts of interest: authors report none.

\section{CORRESPONDING AUTHOR}

Heather Holderness, MPH

Department of Family Medicine

Oregon Health \& Science University

3181 SW Sam Jackson Park Rd

Portland, OR 97239

holdernh@ohsu.edu

\begin{abstract}
PURPOSE Health insurance coverage affects a patient's ability to access optimal care, the percentage of insured patients on a clinic's panel has an impact on the clinic's ability to provide needed health care services, and there are racial and ethnic disparities in coverage in the United States. Thus, we aimed to assess changes in insurance coverage at community health center $(\mathrm{CHC})$ visits after the Patient Protection and Affordable Care Act (ACA) Medicaid expansion by race and ethnicity.
\end{abstract}

METHODS We undertook a retrospective, observational study of visit payment type for $\mathrm{CHC}$ patients aged 19 to 64 years. We used electronic health record data from 10 states that expanded Medicaid and 6 states that did not, $359 \mathrm{CHCs}$, and 870,319 patients with more than 4 million visits. Our analyses included differencein-difference (DD) and difference-in-difference-in-difference (DDD) estimates via generalized estimating equation models. The primary outcome was health insurance type at each visit (Medicaid-insured, uninsured, or privately insured).

RESULTS After the ACA was implemented, uninsured visit rates decreased for all racial and ethnic groups. Hispanic patients experienced the greatest increases in Medicaid-insured visit rates after ACA implementation in expansion states (rate ratio $[R R]=1.77 ; 95 \% \mathrm{Cl}, 1.56-2.02)$ and the largest gains in privately insured visit rates in nonexpansion states ( $\mathrm{RR}=3.63 ; 95 \% \mathrm{Cl}, 2.73-4.83)$. In expansion states, non-Hispanic white patients had twice the magnitude of decrease in uninsured visits compared with Hispanic patients ( $\mathrm{DD}=2.03 ; 95 \% \mathrm{Cl}, 1.53-2.70)$, and this relative change was more than 2 times greater in expansion states compared with nonexpansion states (DDD $=2.06 ; 95 \% \mathrm{Cl}, 1.52-2.78)$.

CONCLUSION The lower rates of uninsured visits for all racial and ethnic groups after ACA implementation suggest progress in expanding coverage to $\mathrm{CHC}$ patients; this progress, however, was not uniform when comparing expansion with nonexpansion states and among all racial and ethnic minority subgroups. These findings suggest the need for continued and more equitable insurance expansion efforts to eliminate health insurance disparities.

Ann Fam Med 2017;15:434-442. https://doi.org/10.1370/afm.2125.

\section{INTRODUCTION}

$\mathrm{H}$ ealth insurance enables access to care and is a major contributor to improved health equity. ${ }^{1.5}$ Community health centers (CHCs) provide health care services to millions of uninsured Americans. ${ }^{6-8}$ Yet, uninsured $\mathrm{CHC}$ patients do not obtain all recommended services. ${ }^{9-12}$ For example, uninsured $\mathrm{CHC}$ patients had $28 \%$ lower odds of receiving recommended diabetes care at visits compared with insured patients. ${ }^{9}$

Historically, racial and ethnic minorities in the United States were less likely to have coverage than the non-Hispanic white population. ${ }^{13,14}$ As a result, the Patient Protection and Affordable Care Act (ACA) was designed, in part, to reduce disparities. ${ }^{15}$ The ACA also mandated that all citizens and legal residents obtain health insurance coverage and included provisions for a national expansion of Medicaid to cover adults earning $138 \%$ or less of the federal poverty level (FPL).$^{16}$ The US Supreme Court, however, ruled that states were not required to expand Medicaid. ${ }^{17}$ Consequently, as 
of April 2016, 32 states and the District of Columbia implemented expansions and 18 states did not. ${ }^{18}$

After ACA implementation, early studies showed an increase in Medicaid enrollment and a decrease in the numbers of uninsured individuals. ${ }^{19-21}$ Although the ACA was predicted to positively affect health insurance disparities among racial and ethnic minorities, ${ }^{22-25}$ results have been mixed. Two studies found health insurance disparities narrowed. ${ }^{26,27}$ Another found that although insurance coverage increased in both expansion and nonexpansion states, compared with the non-Hispanic white patients, uninsured rates declined significantly for black patients in nonexpansion states while they persisted for Hispanic patients in expansion states. ${ }^{28}$

In a previous study, we found a $40 \%$ decrease in uninsured visit rates in expansion states and a $16 \%$ decrease in nonexpansion states ${ }^{29}$; we did not, however, assess whether these gains were equally distributed across racial and ethnic groups. Because $\mathrm{CHCs}$ serve many minority patients, ${ }^{8}$ we expand our earlier work and explore the relationship between the ACA Medicaid expansion and racial and ethnic coverage disparities during a 2-year follow-up period. Given the uncertain future of the ACA, it is crucial to assess the impact of Medicaid expansions on insurance coverage and disparities.

\section{METHODS}

\section{Data Source}

We used electronic health record data from the Accelerating Data Value Across a National Community Health Center Network (ADVANCE) clinical data research network (CDRN) of CHCs in 22 states $^{30}$ for this retrospective, observational study. The ADVANCE CDRN includes a data warehouse based on a common data model with patient-level data in Medicaid expansion and nonexpansion states. ${ }^{30}$

\section{Study Period and Population}

From the ADVANCE CDRN, we included CHC members who were electronic health record users as of January 1, 2013: 225 primary care CHCs in 10 states that expanded Medicaid as of January 1, 2014 (California, Hawaii, Maryland, Minnesota, New Mexico, Ohio, Oregon, Rhode Island, Washington, and Wisconsin) and 134 primary care CHCs in 6 nonexpansion states (Florida, Kansas, Missouri, North Carolina, Texas, Montana). ${ }^{18}$ We included Wisconsin as an expansion state because, although they did not expand Medicaid to $138 \%$ FPL, they opened enrollment to adults with eligibility criteria of $100 \%$ FPL and therefore behaved more like an expansion state. Montana did not expand Medicaid until after our study period ended (expanded January 1, 2016). Our study period included 1 year before (January 1, 2013 to December 31, 2013) through 2 years after ACA Medicaid expansion (January 1, 2014 to December 31, 2015). Analyses included more than 4 million ambulatory visits among patients aged 19 to 64 years.

\section{Variables}

We assessed rates of uninsured, Medicaid-insured, and privately insured primary care visits in the periods after and before Medicaid expansion, overall and temporally, stratified by race and ethnicity. Visit coverage was based on the primary payer listed for each visit, and it was grouped as Medicaid, private, uninsured, or other. Racial and ethnic minority groups were categorized as non-Hispanic white, non-Hispanic black, nonHispanic other race, and Hispanic any race (referred to as Hispanic). Patients with Spanish listed as primary language were included as Hispanic any race regardless of coded ethnicity (less than $2.5 \%$ of our final Hispanic population). Of note, $\mathrm{CHCs}$ are required to report race, ethnicity, and language data to the US Health Resources and Services Administration, so these data are captured for nearly every patient in the ADVANCE database. ADVANCE data, however, contain single response options for patient race, ethnicity, and language (ie, multiple races or multiple languages are not captured, and more granular Hispanic origin information is unavailable). We did not include visits paid by other insurance or the non-Hispanic other group ( $7.7 \%$ of patients) in analyses because of the heterogeneity of these categories.

The primary independent variable was expansion status, that is, whether or not a state expanded Medicaid eligibility as of January $1,2014 .{ }^{18}$

\section{Analysis}

We report demographic information for $\mathrm{CHC}$ visits from expansion and nonexpansion states by race and ethnicity. We computed racial- and ethnic-stratified visit rates by dividing the number of visits in a given interval (numerator) by the total number of patients seen at a given clinic across the study period (denominator) within each racial and ethnic category. Visit rates were scaled per 1,000 patients per month. Visit rates by payment type are reported temporally by month and aggregated to the preexpansion (2013) and postexpansion (2014-2015) periods.

We estimated change from after to before ACA implementation between racial and ethnic group visit rates and expansion states using generalized estimating equation (GEE) Poisson models. The unit of analysis for outcomes was visit rates per 1,000 patients per month for each race and ethnicity group within each clinic site. GEE models included the following indicators: 
postexpansion vs preexpansion, each racial and ethnic group, Medicaid expansion (yes vs no), and all 2-way interactions between those variables. In all our models, we clustered by CHC and used an autoregressive covariance structure to account for within-facility temporal correlation, as well as a robust sandwich variance estimator to account for possible variance-covariance misspecification. Models were adjusted for facility-level demographic distributions (sex, age, and FPL) and statelevel factors (marketplace type, ${ }^{31} 2014$ minimum wage ${ }^{32}$ and unemployment rate, ${ }^{33}$ and 2013 uninsured rate $^{34}$ ). Linear combinations of regression parameters were constructed to estimate difference-in-difference (DD) (postexpansion vs preexpansion rate ratios between racial and ethnic groups within their own expansion group, and postexpansion vs preexpansion rate ratios within racial and ethnic groups between expansion and nonexpansion states) and difference-in-differencein-difference (DDD) (postexpansion vs preexpansion changes by racial and ethnic groups for expansion states vs nonexpansion states). The reference groups for DDD estimates were preexpansion period, non-Hispanic white patients, and nonexpansion states, respectively. Where appropriate, we coded missing categories to avoid dropping observations from analyses.

Statistical testing was 2 -sided, and significance was set at $P<.05$. All statistical analyses were completed using SAS version 9.3 (SAS Institute Inc). This study was reviewed and approved by the Oregon Health \& Science University Institutional Review Board.

\section{RESULTS \\ Demographic Characteristics}

In the nonexpansion states, there were $134 \mathrm{CHCs}$ with 370,600 patients and 1,478,445 primary care visits (Table 1). In the expansion states, there were $225 \mathrm{CHCs}$ with 499,719 patients and 2,612,986 primary care visits. Nonexpansion states in our sample had a greater proportion of non-Hispanic black patients (25.0\%) and Hispanic patients $(38.5 \%)$ than expansion states (nonHispanic black patients, $10.9 \%$, and Hispanic patients, $30.7 \%$ ). In all states, there were more female than male patients. Most patients had a household income

Table 1. Demographic Characteristics in 6 Nonexpansion and 10 Expansion States by Racial and Ethnic Group (2013-2015)

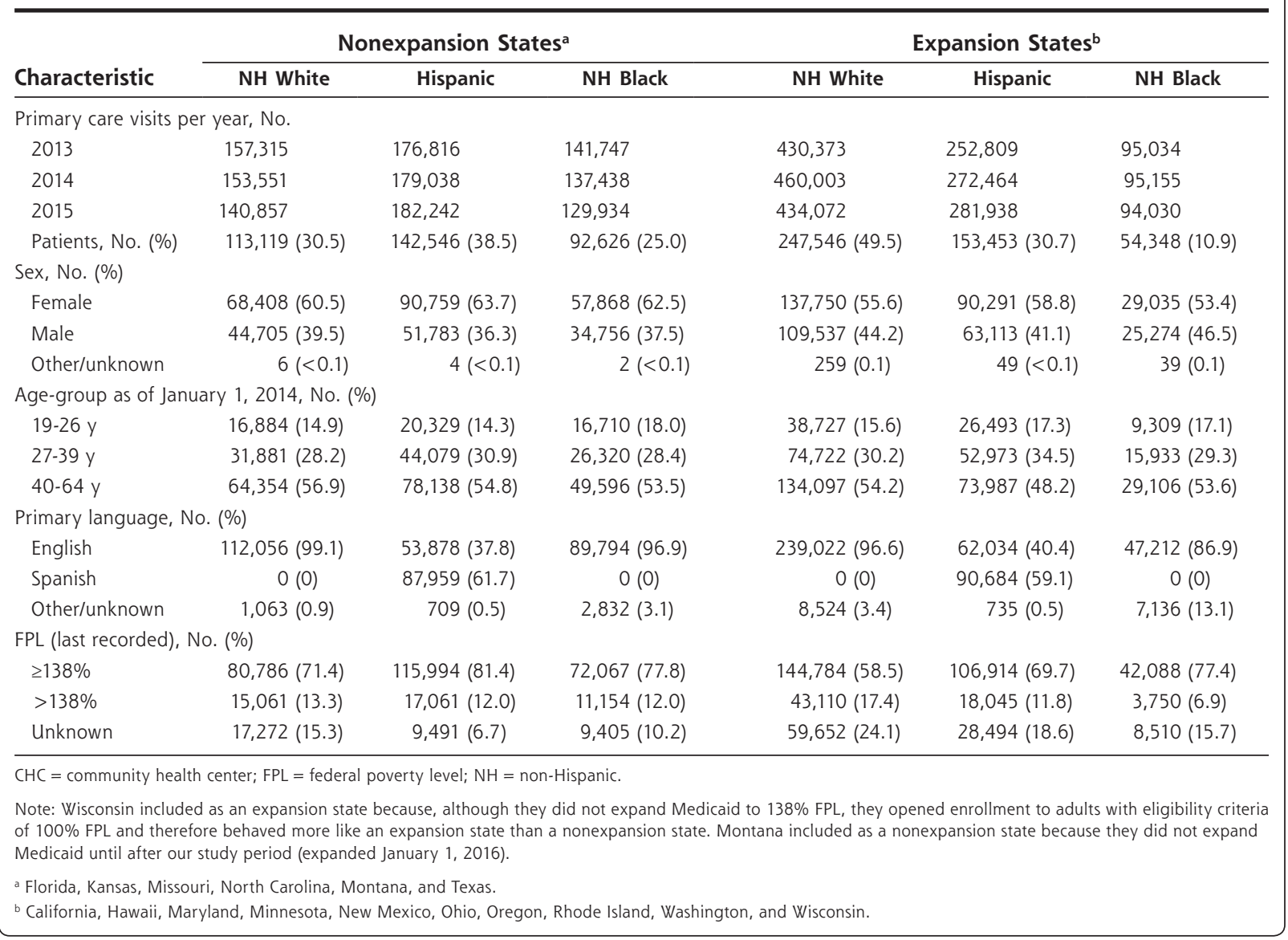


of $138 \%$ or less of the FPL, with the highest percentage among Hispanic patients in nonexpansion states and non-Hispanic black patients in nonexpansion and expansion states. There was no significant difference in the overall rate of primary care visits for any racial and ethnic group from before to after ACA Medicaid expansion (data not shown).

\section{Rates of Payment Type for Primary Care Visits by Racial and Ethnic Groups (2013-2015)}

Rates of Medicaid-insured visits increased in expansion states for all racial and ethnic groups immediately after ACA Medicaid expansion, whereas no change was observed for Medicaid-insured visits for any racial and ethnic group in nonexpansion states.

Rates of uninsured visits decreased for all racial and ethnic groups in both expansion and nonexpansion

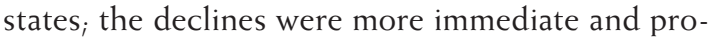
nounced in expansion states.

For privately insured visits, the largest changes after expansion were seen in nonexpansion states where all 3 racial and ethnic groups had increases; privately insured visit rates among Hispanic patients continued to increase throughout the second year after ACA implementation, whereas they stabilized for the other 2 racial and ethnic groups (Figure 1).

Figure 1. Rates of payment type for primary care visits by race and and ethnicity.
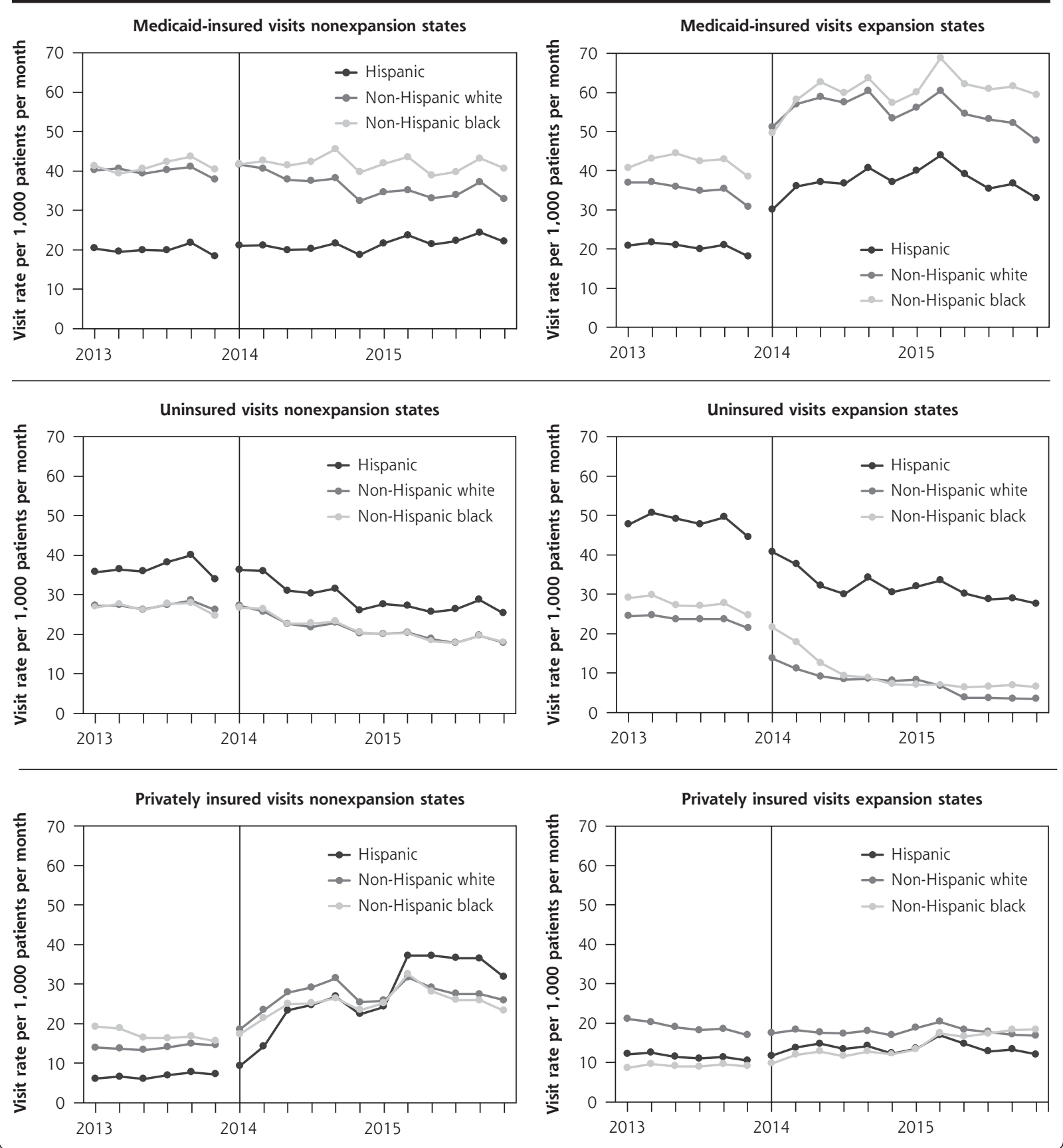
Racial and Ethnic Differences in Visit Payment Type From Before to After ACA Implementation Within Expansion and Nonexpansion States

Expansion States

Rates of Medicaid-insured visits in expansion states increased $60 \%$ from after ACA implementation among the non-Hispanic white patients $(\mathrm{RR}=1.60 ; 95 \% \mathrm{CI}, 1.44-1.78)$, $77 \%$ for Hispanic patients $(\mathrm{RR}=1.77$; 95\% CI, 1.56-2.02), and $40 \%$ for non-Hispanic black patients $(\mathrm{RR}=1.40 ; 95 \%$ CI, 1.23-1.61). Although all racial and ethnic groups had increases in Medicaid-insured visit rates after implementation, no group significantly increased more than the other groups, as evidenced by nonsignificant DD estimates. Uninsured-visit rates decreased in all groups: non-Hispanic white patients had the largest decrease of about $68 \%$ $(\mathrm{RR}=0.32 ; 95 \% \mathrm{CI}, 0.25-0.42)$, a decline approximately twofold greater than Hispanic patients in the same states $(\mathrm{DD}=2.03 ; 95 \% \mathrm{CI}, 1.53$ 2.70). Hispanic patients had a significantly higher rate of privately insured visits in the after implementation period $(\mathrm{RR}=1.22 ; 95 \% \mathrm{CI}, 1.05-1.41)$, which was $25 \%$ greater than the change for non-Hispanic white patients $(\mathrm{DD}=1.25$; 95\% CI, 1.04-1.51). Changes in visit rates were similar between non-Hispanic black and nonHispanic white patients on all outcomes (Table 2).

\section{Nonexpansion States}

In nonexpansion states, the rates of Medicaid-insured visits across racial and ethnic groups did not significantly change after implementation periods. All racial and ethnic groups experienced a similar decline in uninsured visit rates, approximately $20 \%$ lower in the period after implementation, with no significant differences between racial and ethnic groups. The most notable changes in nonexpansion states were in private insur-
Table 2. Primary Care Visit Rates by Payment Type and Race and Ethnicity: Expansion States

\begin{tabular}{|c|c|c|c|c|}
\hline Payment Type & $\begin{array}{c}\text { Pre-ACA } \\
\text { Rate }\end{array}$ & $\begin{array}{c}\text { Post-ACA } \\
\text { Rate }\end{array}$ & $\begin{array}{c}\text { Post- vs Pre-ACA } \\
\text { Within-Race } \\
\text { RR }(95 \% \mathrm{Cl})\end{array}$ & $\begin{array}{c}\text { Post- vs Pre-ACA } \\
\text { Between Race } \\
\text { DD }(95 \% \mathrm{CI})\end{array}$ \\
\hline \multicolumn{5}{|l|}{ Medicaid-insured } \\
\hline $\mathrm{NH}$ white & 34.25 & 54.76 & $1.60(1.44-1.78)^{\mathrm{a}}$ & 1 [Reference] \\
\hline Hispanic & 21.96 & 38.91 & $1.77(1.56-2.02)^{\mathrm{a}}$ & $1.11(0.96-1.28)$ \\
\hline $\mathrm{NH}$ black & 42.95 & 60.26 & $1.40(1.23-1.61)^{\mathrm{a}}$ & $0.88(0.75-1.03)$ \\
\hline \multicolumn{5}{|l|}{ Uninsured } \\
\hline $\mathrm{NH}$ white & 23.95 & 7.73 & $0.32(0.25-0.42)^{\mathrm{a}}$ & 1 [Reference] \\
\hline Hispanic & 46.61 & 30.54 & $0.66(0.58-0.74)^{a}$ & $2.03(1.53-2.70)^{b}$ \\
\hline $\mathrm{NH}$ black & 28.12 & 11.46 & $0.41(0.35-0.48)^{\mathrm{a}}$ & $1.26(0.92-1.73)$ \\
\hline \multicolumn{5}{|l|}{ Privately insured } \\
\hline $\mathrm{NH}$ white & 19.53 & 18.94 & $0.97(0.84-1.12)$ & 1 [Reference] \\
\hline Hispanic & 12.33 & 14.99 & $1.22(1.05-1.41)^{\mathrm{a}}$ & $1.25(1.04-1.51)^{b}$ \\
\hline $\mathrm{NH}$ black & 10.31 & 11.70 & $1.14(0.91-1.42)$ & $1.17(0.91-1.51)$ \\
\hline
\end{tabular}

$\mathrm{ACA}=$ Patient Protection and Affordable Care Act; DD = difference-in-difference; $\mathrm{NH}=$ non-Hispanic; $\mathrm{RR}=$ rate ratio. Note: Generalized estimating equation models were adjusted for facility-level demographic distributions (sex, age, and federal poverty level) and state-level factors (marketplace type, 2014 minimum wage and unemployment rates, and 2013 uninsured rate), clustered by facility to account for within-facility correlation. Visit rates presented per 1,000 patients per month. DD estimates compare change between racial and ethnic groups (reference $=\mathrm{NH}$ white) within expansion states before and after ACA Medicaid expansion.

a Statistically significant change post- vs pre-ACA RR, $P<.05$.

${ }^{b}$ Statistically significant DD estimates (reference: pre-ACA, NH white), $P<.05$

Table 3. Primary Care Visit Rates by Payment Type and Race and Ethnicity: Nonexpansion States

\begin{tabular}{|c|c|c|c|c|}
\hline Payment Type & $\begin{array}{c}\text { Pre-ACA } \\
\text { Rate }\end{array}$ & $\begin{array}{c}\text { Post-ACA } \\
\text { Rate }\end{array}$ & $\begin{array}{c}\text { Post- vs Pre-ACA } \\
\text { Within Race } \\
\text { RR }(95 \% \mathrm{Cl})\end{array}$ & $\begin{array}{c}\text { Post- vs Pre-ACA } \\
\text { Between Race } \\
\text { DD }(95 \% \mathrm{CI})\end{array}$ \\
\hline \multicolumn{5}{|l|}{ Medicaid-insured } \\
\hline $\mathrm{NH}$ white & 35.61 & 33.64 & $0.95(0.84-1.07)$ & 1 [Reference] \\
\hline Hispanic & 20.19 & 20.00 & $0.99(0.89-1.10)$ & $1.05(0.92-1.20)$ \\
\hline $\mathrm{NH}$ black & 38.70 & 37.59 & $0.97(0.90-1.05)$ & $1.03(0.91-1.17)$ \\
\hline \multicolumn{5}{|l|}{ Uninsured } \\
\hline $\mathrm{NH}$ white & 31.75 & 25.36 & $0.80(0.73-0.87)^{a}$ & 1 [Reference] \\
\hline Hispanic & 43.14 & 34.05 & $0.79(0.71-0.87)^{\mathrm{a}}$ & $0.99(0.89-1.10)$ \\
\hline $\mathrm{NH}$ black & 31.57 & 25.36 & $0.80(0.69-0.94)^{a}$ & $1.01(0.87-1.17)$ \\
\hline \multicolumn{5}{|l|}{ Privately insured } \\
\hline $\mathrm{NH}$ white & 12.70 & 23.35 & $1.84(1.46-2.32)^{\mathrm{a}}$ & 1 [Reference] \\
\hline Hispanic & 5.52 & 20.05 & $3.63(2.73-4.83)^{\mathrm{a}}$ & $1.97(1.43-2.72)^{\mathrm{b}}$ \\
\hline $\mathrm{NH}$ black & 11.43 & 20.57 & $1.80(1.40-2.32)^{\mathrm{a}}$ & $0.98(0.78-1.23)$ \\
\hline \multicolumn{5}{|c|}{$\mathrm{ACA}=$ Patient Protection and Affordable Care Act; $\mathrm{DD}=$ difference-in-difference; $\mathrm{NH}=$ non-Hispanic; $\mathrm{RR}=$ rate ratio. } \\
\hline \multicolumn{5}{|c|}{$\begin{array}{l}\text { Note: Generalized estimating equation models were adjusted for facility-level demographic distributions (sex, age, } \\
\text { and federal poverty level) and state-level factors (marketplace type, } 2014 \text { minimum wage and unemployment rates, } \\
\text { and } 2013 \text { uninsured rate), clustered by facility to account for within-facility correlation. Visit rates presented per } \\
1,000 \text { patients per month. DD estimates compare change between racial and ethnic groups (reference = NH white) } \\
\text { within nonexpansion states before and after ACA Medicaid expansion. }\end{array}$} \\
\hline
\end{tabular}


ance visit rates: all racial and ethnic groups increased significantly after ACA implementation, with Hispanic patients utilizing $\mathrm{CHC}$ with private coverage at 3.6 times their rate in the preimplementation period. This increase was significantly greater for Hispanic patients relative to non-Hispanic white patients in nonexpansion states $(\mathrm{DD}=1.97 ; 95 \% \mathrm{CI}, 1.43-2.72)$ (Table 3$)$.

\section{Racial and Ethnic Differences in Visit Payment Type After ACA Implementation Between Expansion and Nonexpansion States}

Changes in Medicaid-insured visit rates were significantly greater in expansion than in nonexpansion states for all racial and ethnic groups; Hispanic patients had the greatest relative increase $(\mathrm{DD}=1.79 ; 95 \% \mathrm{CI}, 1.51$ 2.12), but these changes were not significantly different for either minority group relative to non-Hispanic white patients (DDD; $P>.05$ for both). Likewise, the decrease in uninsured visit rates after implementation was significantly greater in expansion than in nonexpansion states for all racial and ethnic groups, with non-Hispanic white patients having the greatest relative decrease $(\mathrm{DD}=0.40 ; 95 \% \mathrm{CI}, 0.31-0.54$ ) and Hispanic patients having the smallest difference between expansion groups (DD $=0.83 ; 95 \% \mathrm{CI}, 0.71$ 0.98). Non-Hispanic white patients had a significantly greater decrease of uninsured rates relative to Hispanic patients in expansion states when compared with nonexpansion states (DDD $=2.06 ; 95 \% \mathrm{CI}, 1.52-2.78$ ). Nonexpansion states had greater increases after ACA implementation in privately insured visits, with Hispanic patients experiencing the greatest relative change of the racial and ethnic groups (DD $=0.34 ; 95 \% \mathrm{CI}$, 0.24-0.46; DDD $=0.64 ; 95 \% \mathrm{CI}, 0.44-0.92)$ (Figure 2).

\section{DISCUSSION}

Our study showed the ACA Medicaid expansion contributed to sizeable decreases in uninsured $\mathrm{CHC}$ visit rates for all racial and ethnic groups, a finding that is consistent with previous research. ${ }^{22,25,26}$ Our use of electronic health record data strengthens the accuracy of these results. ${ }^{35,36}$ Although we found improvements across all racial and ethnic groups, important disparities remain. For example, Hispanic patients maintained the highest uninsured visit rates, and the decline in uninsured visits was significantly less for this group than for non-Hispanic white and non-Hispanic black patients after Medicaid expansion. The most likely reason is only US citizens and legal residents are eligible for Medicaid coverage, and it is estimated that there are up to 6 million unauthorized Hispanic

Figure 2. Payment visit type after ACA implementation by race and ethnicity.

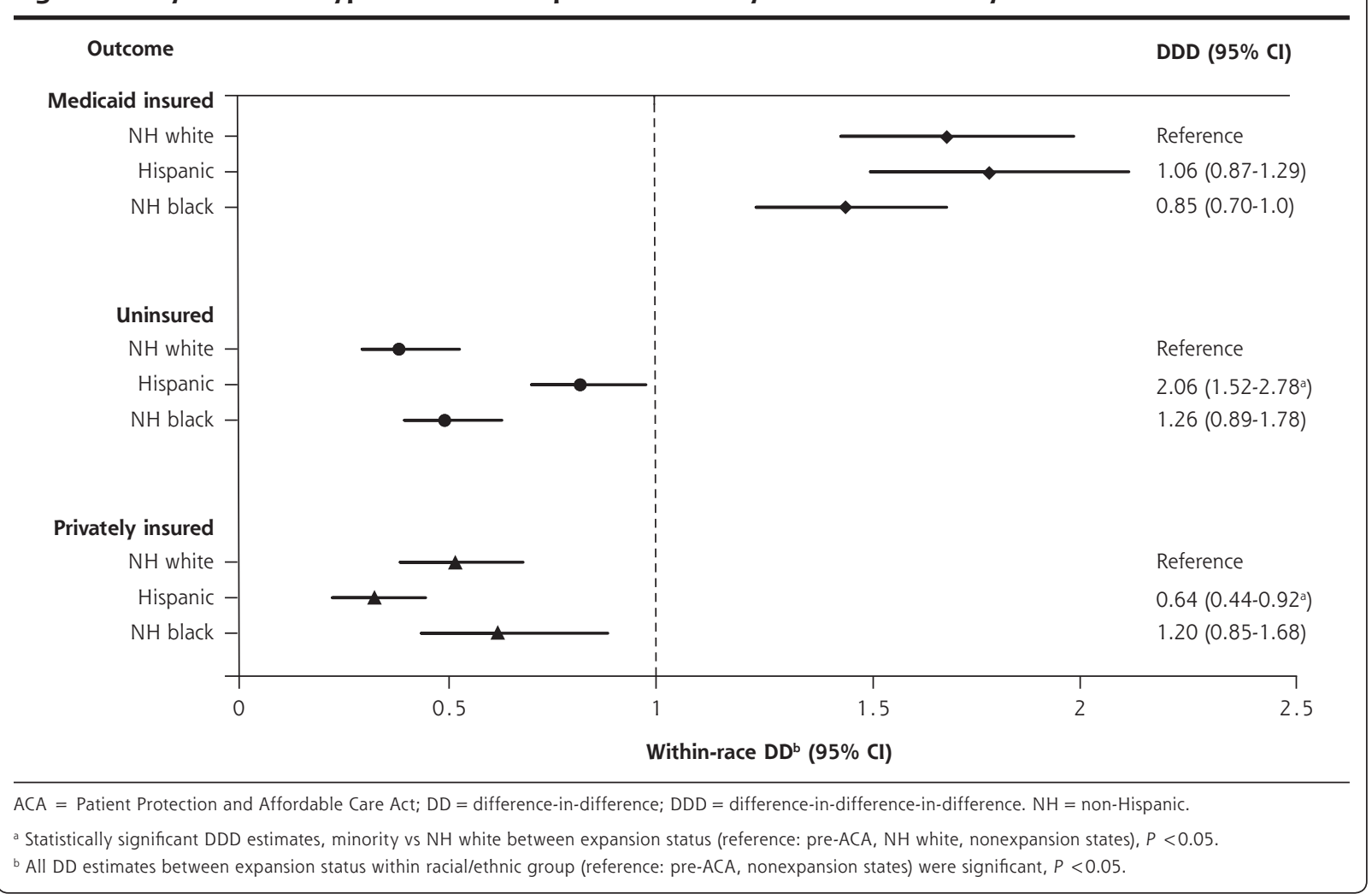


immigrants living in the United States as of $2014 .^{37}$ Another reason for these continued differences, as suggested by Buchmueller et al, is that income is a major driver of racial and ethnic disparities in coverage. ${ }^{26}$ Lastly, Hispanic patients were not as aware of potential insurance options compared with white and black patients. ${ }^{38,39}$

Nonexpansion states did not see significant differences in Medicaid-insured visits for any racial and ethnic group. Conversely, expansion states saw large increases in Medicaid-insured visits for all racial and ethnic groups. Yet, Hispanic patients continued to have the lowest rates of Medicaid-insured visits compared with non-Hispanic white and non-Hispanic black patients. This finding suggests that gaps in Medicaid coverage have continued for Hispanic patients, while the disparities have been reduced for non-Hispanic black patients. Nonetheless, previous research found that although members of racial and ethnic populations make up $41 \%$ of the population, they account for more than $50 \%$ of those who remain uninsured after expansion. ${ }^{40}$

Privately insured visits increased for all racial and ethnic groups in nonexpansion states, whereas they remained mostly stable in expansion states. This increase was most pronounced among Hispanic patients. The sharper increase in privately-covered visits among Hispanic patients may suggest that fewer of these patients were eligible for Medicaid and thus sought private coverage to comply with the individual mandate. These results also suggest that health insurance marketplaces were effective in helping some patients find coverage. There is, however, a documented coverage gap wherein some individuals have incomes too high for Medicaid eligibility but too low for subsidized private coverage, with 3 million adults likely to remain uninsured in states that did not expand Medicaid. ${ }^{41}$

\section{Implications for Patients and CHCs}

Even among $\mathrm{CHC}$ patients, health insurance coverage affects a patient's ability to access optimal care. For example, newly Medicaid-insured CHC patients received more smoking medication orders and quit smoking at higher rates than their counterparts who remained uninsured. ${ }^{42}$ Gaining Medicaid coverage was associated with increased receipt of recommended preventive care for CHC patients. ${ }^{43}$ Additionally, patients with diabetes and hypertension were significantly more likely to gain control of uncontrolled hemoglobin $A_{1 c}$ levels and blood pressure readings when comparing insured with matched uninsured $\mathrm{CHC}$ patients. ${ }^{44}$

The percentage of insured patients seen in a clinic also affects the clinic's ability to provide needed health care services to all patients. ${ }^{45,46}$ For example, CHCs with a higher percentage of insured patients provided all patients with superior levels of recommended care than clinics caring for a lower percentage of insured patients. ${ }^{45}$ ACA Medicaid expansion was also associated with improved receipt of recommended care at $\mathrm{CHCs}^{46}$ and allowed $\mathrm{CHC}$ s to serve more patients: 21.7 million patients in 2013, up from 8.1 million patients in $1996 .{ }^{47}$ As $\mathrm{CHC}$ s recover more of the costs of care from insurance payments, they may be able to stretch federal grant dollars to conduct quality improvement initiatives. Improving their ratio of insured to uninsured patients is especially important, because $\mathrm{CHC}$ patient populations tend to be sicker and more complex than non-CHC patients and because CHCs continue to care for more patients. ${ }^{8}$

Based on mounting evidence that health insurance plays a role in access to recommended health care, $, 111,42,45,46$ our findings suggest equitable access, even in CHCs, depends on equality in health insurance coverage. Additional research is needed to understand more fully how recent insurance changes have affected access to health care services and whether the effect differs by patients' race or ethnic background. As the future of the ACA is unknown, it is imperative that we understand its impact to date.

\section{Limitations}

This study is based on CHCs that are part of the ADVANCE CDRN. Because some of the states in our sample are represented by only a few $\mathrm{CHCs}$, our results may not represent postexpansion Medicaid experiences of all states or expansion status groups. The profile of CHC patients in the ADVANCE CDRN, however, is comparable to national estimates of $\mathrm{CHC}$ patients. ${ }^{48}$ Our racial and ethnic groups do not represent all groups, nor do they account for the heterogeneity within each group. We could not ascertain Hispanic origin (eg, Mexican, Puerto Rican, etc), nor could we identify Hispanic patients who were not eligible for Medicaid coverage because of immigration status. The payer distributions in our study are different from other primary care settings, so additional research to determine whether similar progress was made in reducing racial and ethnic disparities in non$\mathrm{CHC}$ settings is needed. It is also possible that once insured, $\mathrm{CHC}$ patients left the safety net for private clinics. Yet, most non-CHC clinicians are not accepting new patients with Medicaid, ${ }^{49}$ and national data suggest that more than $90 \%$ of all patients, regardless of insurance status, do not change their place of care within a 12 -month period. ${ }^{50}$ Our analysis is visit based and does not assess changes in patient-level insurance coverage, nor does it account for differences in health 
care needs. We adjusted our multivariable analysis to account for economic differences between expansion and nonexpansion states, yet unmeasured confounders could impact our results.

In $\mathrm{CHCs}$, the ACA Medicaid reform contributed to lower uninsured visit rates for all racial and ethnic groups, suggesting that the ACA is having its intended effect on expanding health insurance coverage to more patients. Differences, however, in Medicaid-insured, privately insured, and uninsured visit rates in expansion compared with nonexpansion states and among racial and ethnic minority patients remain, indicating equity has not yet been achieved.

\section{To read or post commentaries in response to this article, see it} online at http://www.AnnFamMed.org/content/15/5/434.

Key words: Patient Protection and Affordable Care Act; Medicaid; health policy; health insurance; health care disparities

Submitted December 16, 2016; submitted, revised, May 24, 2017; accepted July 3, 2017.

Funding support: This work was supported by the Agency for Healthcare Research and Quality grant number R01HS024270 and by the National Cancer Institute grant numbers R01CA204267 and R01CA181452. This publication was also made possible by Cooperative Agreement Number U18DP006116 jointly funded by the US Centers for Disease Control and Prevention and the National Institute of Diabetes and Digestive and Kidney Disease, and Patient-Centered Outcomes Research Institute (PCORI). Accelerating Data Value Across a National Community Health Center Network (ADVANCE) is funded by PCORI and led by the OCHIN Community Health Information Network in partnership with the Health Choice Network, Fenway Health, CareOregon, Kaiser Permanente Center for Health Research, Legacy Health, Oregon Health \& Science University, and the Robert Graham Center.

Disclaimer: The views presented in this article are solely the responsibility of the authors and do not necessarily represent the views of the funding agencies.

Acknowledgments: The authors acknowledge the significant contributions to this study that were provided by collaborating investigators in the Natural Experiments in Translation for Diabetes Study Two. The authors also acknowledge the participation of our partnering health systems.

Previous presentation: Part of this manuscript was presented at the North American Primary Care Research Group 44th Annual Meeting; November 12-16, 2016; Colorado Springs, Colorado.

\section{Clinical Trials Registration: NCT02657499}

\section{References}

1. Asplin BR, Rhodes KV, Levy $\mathrm{H}$, et al. Insurance status and access to urgent ambulatory care follow-up appointments. JAMA. 2005; 294(10):1248-1254

2. Burstin HR, Lipsitz SR, Brennan TA. Socioeconomic status and risk for substandard medical care. JAMA. 1992;268(17):2383-2387.

3. Jerant A, Fiscella K, Tancredi DJ, Franks P. Health insurance is associated with preventive care but not personal health behaviors. J Am Board Fam Med. 2013;26(6):759-767.
4. Pande AH, Ross-Degnan D, Zaslavsky AM, Salomon JA. Effects of healthcare reforms on coverage, access, and disparities: quasiexperimental analysis of evidence from Massachusetts. Am J Prev Med. 2011;41(1):1-8.

5. Ayanian JZ, Weissman JS, Schneider EC, Ginsburg JA, Zaslavsky AM. Unmet health needs of uninsured adults in the United States. JAMA. 2000;284(16):2061-2069.

6. Shi L, Stevens GD. The role of community health centers in delivering primary care to the underserved: experiences of the uninsured and Medicaid insured. J Ambul Care Manage. 2007;30(2):159-170.

7. Goldman LE, Chu PW, Tran H, Romano MJ, Stafford RS. Federally qualified health centers and private practice performance on ambulatory care measures. Am J Prev Med. 2012;43(2):142-149.

8. National Association of Community Health Centers. A Sketch of Community Health Centers, Chartbook 2016. Bethesda, MD: National Association of Community Health Centers; 2016.

9. Bailey SR, O’Malley JP, Gold R, Heintzman J, Marino M, DeVoe JE. Receipt of diabetes preventive services differs by insurance status at visit. Am J Prev Med. 2015;48(2):229-233.

10. Gold R, Bailey SR, O'Malley JP, et al. Estimating demand for care after a medicaid expansion: lessons from Oregon. J Ambul Care Manage. 2014;37(4):282-292.

11. Gold R, DeVoe J, Shah A, Chauvie S. Insurance continuity and receipt of diabetes preventive care in a network of federally qualified health centers. Med Care. 2009;47(4):431-439.

12. Nelson KM, Chapko MK, Reiber G, Boyko EJ. The association between health insurance coverage and diabetes care; data from the 2000 Behavioral Risk Factor Surveillance System. Health Serv Res. 2005;40(2):361-372.

13. Institute of Medicine US, Committee on Understanding and Eliminating Racial and Ethnic Disparities in Health Care. Unequal Treatment: Confronting Racial and Ethnic Disparities in Health Care. Washington, DC: National Academies Press (US); 2003.

14. Agency for Healthcare Research and Quality. 2012 National Healthcare Disparities Report. Rockville, MD: Agency for Healthcare Research and Quality, U.S. Department of Health and Human Services; 2013

15. Sealy-Jefferson S, Vickers J, Elam A, Wilson MR. Racial and ethnic health disparities and the Affordable Care Act: a status update. J Racial Ethn Health Disparities. 2015;2(4):583-588.

16. The Henry J. Kaiser Family Foundation. Summary of the Affordable Care Act. Menlo Park, CA: The Henry J. Kaiser Family Foundation; 2013.

17. National Federation of Independent Business v. Sebelius, 567 US 519, (2012).

18. The Henry J. Kaiser Family Foundation. Status of State Action on the Medicaid Expansion Decision. Menlo Park, CA: The Henry J. Kaiser Family Foundation; 2015.

19. Shin P, Sharac J, Zur J, Rosenbaum S, Paradise J. Health Center Patient Trends, Enrollment Activities, and Service Capacity: Recent Experience in Medicaid Expansion and Non-Expansion States. Menlo Park, CA: The Henry J. Kaiser Family Foundation; 2015.

20. Obama B. United states health care reform: Progress to date and next steps. JAMA. 2016;316(5):525-532.

21. Wherry LR, Miller S. Early coverage, access, utilization, and health effects associated with the Affordable Care Act Medicaid expansions: a quasi-experimental study. Ann Intern Med. 2016;164(12): 795-803.

22. Ku L, Jones K, Shin P, Bruen B, Hayes K. The states' next challenge-securing primary care for expanded Medicaid populations. N Engl J Med. 2011;364(6):493-495.

23. Alegria M, Lin J, Chen CN, Duan N, Cook B, Meng XL. The impact of insurance coverage in diminishing racial and ethnic disparities in behavioral health services. Health Serv Res. 2012;47(3 Pt 2):1322-1344. 
24. Shane DM, Ayyagari P. Will health care reform reduce disparities in insurance coverage?: Evidence from the dependent coverage mandate. Med Care. 2014;52(6):528-534.

25. Chen J, Vargas-Bustamante A, Mortensen K, Ortega AN. Racial and ethnic disparities in health care access and utilization under the Affordable Care Act. Med Care. 2016;54(2):140-146.

26. Buchmueller TC, Levinson ZM, Levy HG, Wolfe BL. Effect of the Affordable Care Act on racial and ethnic disparities in health insurance coverage. Am J Public Health. 2016;106(8):1416-1421.

27. Heintzman J, Bailey SR, DeVoe J, et al. In Low-income Latino patients, post-Affordable Care Act insurance disparities may be reduced even more than broader national estimates: evidence from Oregon. J Racial Ethn Health Disparities. 2017;4(3):329-336.

28. McMorrow S, Long SK, Kenney GM, Anderson N. Uninsurance disparities have narrowed for black and Hispanic adults under the Affordable Care Act. Health Aff (Millwood). 2015;34(10):1774-1778.

29. Angier H, Hoopes M, Gold R, et al. An early look at rates of uninsured safety net clinic visits after the Affordable Care Act. Ann Fam Med. 2015;13(1):10-16.

30. DeVoe JE, Gold R, Cottrell E, et al. The ADVANCE network: accelerating data value across a national community health center network. J Am Med Inform Assoc. 2014;21(4):591-595.

31. Henry J. Kaiser Family Foundation. Total marketplace enrollment. http://www.kff.org/health-reform/state-indicator/ total-marketplace-enrollment/.

32. CNN. 2014 minimum wage, state by state. CNN Money. http:// money.cnn.com/interactive/pf/state-minimum-wage/.

33. Bureau of Labor Statistics. Current Unemployment Rates for States and Historical Highs/Lows. Washington, DC: US Department of Labor; 2014.

34. Witters D. Highest uninsured states less likely to embrace health law. Gallup. http://www.gallup.com/poll/167321/highest-uninsuredstates-less-likely-embrace-health-law.aspx. Published Feb 7, 2014.

35. Pascale J, Call K, Fertig A, Oellerich D. Validating self-reported health insurance coverage: preliminary results on CPS and ACS. U.S. Census Bureau, Research Matters. https://www.census.gov/ newsroom/blogs/research-matters/2016/05/validating-self-reportedhealth-insurance-coverage-preliminary-results-on-cps-and-acs.html. Published May 14, 2016.

36. Ritter PL, Stewart AL, Kaymaz H, Sobel DS, Block DA, Lorig KR. Self-reports of health care utilization compared to provider records. J Clin Epidemiol. 2001;54(2):136-141.

37. Krogstad JM, Passel JS, Cohn DV. 5 facts about illegal immigration in the U.S. Pew Research Center. http://www. pewresearch.org/ fact-tank/2017/04/27/5-facts-about-illegal-immigration-in-the-u-s/. Published Apr 27, 2017.
38. Garcia Mosqueira A, Hua LM, Sommers BD. Racial differences in awareness of the Affordable Care Act and application assistance among low-income adults in three southern states. Inquiry. 2015; 52(52):1-4.

39. Artiga S, Damico A, Garfield R. Estimates of Eligibility for ACA Coverage among the Uninsured by Race and Ethnicity. Menlo Park, CA: The Henry J. Kaiser Family Foundation; 2015.

40. The Henry J. Kaiser Family Foundation. Key Facts About the Uninsured Population. Menlo Park, CA: The Henry J. Kaiser Family Foundation; 2016. http://www.kff.org/uninsured/fact-sheet/ key-facts-about-the-uninsured-population/.

41. Garfield R, Damico A. The Coverage Gap: Uninsured Poor Adults in States that Do Not Expand Medicaid - An Update. Menlo Park, CA: The Henry J. Kaiser Family Foundation; 2016.

42. Bailey SR, Hoopes MJ, Marino M, et al. Effect of gaining insurance coverage on smoking cessation in community health centers: a cohort study. J Gen Intern Med. 2016;31(10):1198-1205.

43. Marino M, Bailey SR, Gold R, et al. Receipt of preventive services after Oregon's randomized Medicaid experiment. Am J Prev Med. 2016;50(2):161-170

44. Hatch B, Marino M, Killerby M, et al. Medicaid's impact on chronic disease biomarkers: a cohort study of community health center patients. J Gen Intern Med. 2017;32(8):940-947.

45. Bailey SR, O'Malley JP, Gold R, Heintzman J, Likumahuwa S, DeVoe JE. Diabetes care quality is highly correlated with patient panel characteristics. J Am Board Fam Med. 2013;26(6):669-679.

46. Cole MB, Galárraga O, Wilson IB, Wright B, Trivedi AN. At federally funded health centers, Medicaid expansion was associated with improved quality of care. Health Aff (Millwood). 2017;36(1):40-48.

47. Shin P, Sharac J, Rosenbaum S. Community health centers and Medicaid at 50: an enduring relationship essential for health system transformation. Health Aff (Millwood). 2015;34(7):1096-1104.

48. National Association of Community Health Centers. America's Health Centers. Bethesda, MD: National Association of Community Health Centers; 2016.

49. Decker SL. In 2011 nearly one-third of physicians said they would not accept new Medicaid patients, but rising fees may help. Health Aff (Millwood). 2012;31(8):1673-1679.

50. National Center for Health Statistics. National Health Interview Survey, 2012. Public-use data file and documentation. Hyattsville, MD: National Center for Health Statistics; 2014. 